\title{
Prevalence of Inhibitor Resistant Beta Lactamase Producing E. coli in Human and Poultry Origin of Bangladesh
}

Md. Anowar Khasru Parvez ${ }^{1 *}$, Mahfuza Marzan ${ }^{1}$, Syeda Moriam Liza ${ }^{1}$, Taslin Jahan Mou ${ }^{1}$, Ishrat Jahan Azmi ${ }^{2}$, Md. Shahedur Rahman ${ }^{3}$ and Zahid Hayat Mahmud $^{4}$

${ }^{1}$ Department of Microbiology, Jahangirnagar University, Dhaka, Bangladesh

${ }^{2}$ Enteric Laboratory, icddr, b, Dhaka, Bangladesh

${ }^{3}$ Department of Genetic Engineering and Biotechnology, Jessore University of Science and Technology, Jessore, Bangladesh

${ }^{4}$ Environmental Microbiology Laboratory, Center for Food and Water Borne Diseases, icddr, b, Dhaka, Bangladesh

"Corresponding author: Md. Anowar Khasru Parvez, Department of Microbiology, Jahangirnagar University, Dhaka-1342, Bangladesh, Tel: +88027791045.1566 (off); Fax: 880-2-7791052; E-mail: khasru73@juniv.edu

Received date: March 29, 2016; Accepted date: April 21, 2016; Published date: April 29, 2016

Copyright: () 2016 Parvez Md. AK, et al. This is an open-access article distributed under the terms of the Creative Commons Attribution License, which permits unrestricted use, distribution, and reproduction in any medium, provided the original author and source are credited.

\begin{abstract}
Human clinical specimens $(n=48)$ and poultry fecal specimens $(n=40)$ were collected from a sub district (Savar) of Bangladesh. Total $25 \mathrm{E}$. coli were isolated from these specimens. These $E$. coli were tested for their antibiotic sensitivity against commonly used antibiotics. In addition, to detect the ESBL (extended spectrum beta lactamases) producers, double disk synergy (DDS) test and PCR method were used. Twenty three E. coli were multidrug resistant, i.e. resistant against at least three different groups of antibiotics. DDS method showed all E. coli from poultry specimens and $78 \%$ of $E$. coli from clinical specimens were resistant to amoxicillin-clavulanic acid combination. Thus they are phenotypically confirmed as inhibitor resistant beta lactamase producers. PCR result showed only blaTEMgene in $E$. coli from poultry specimens. Thus inhibitor resistant type $\beta$-lactamase was found to be dominant in $E$. coli from both types of specimens.
\end{abstract}

Keywords: MDR; E. coli; Inhibitor resistant $\beta$-lactamase

\section{Introduction}

In Bangladesh high prevalence of multidrug resistant (MDR) and extended spectrum beta-lactamase (ESBL) producing bacteria in clinical specimens, hospital waste water, and drinking water samples have been reported [1-3]. The control of infection of human with Gram negative pathogenic bacteria (e.g. Enterobacteriaceae) can be seriously affected by high prevalence of antibiotic resistance and ESBL producing nature [4]. In developing countries like Bangladesh, the availability and indiscriminate use of antibiotics in clinical and nonclinical purposes increases the chance of antimicrobial exposure of the microorganisms and thus the inevitable increase in antibiotic resistance [5]. Among the various sectors in Bangladesh, poultry industry is one of the sectors where antibiotic misuse is common and thereby, have generated selection pressure towards antimicrobial resistance [6]. In fact, current data of Bangladesh have indicated presence of resistant and ESBL producing bacteria among poultry and household birds $[7,8]$. Recently in different countries poultry has been identified as a potential reservoir of resistant bacteria and transfer of resistance from non-pathogenic bacteria to pathogens and vice versa can happen $[9,10]$. In Bangladesh there is limited data on this perspective.

The aim of this study was to isolate and identify MDR and ESBL producing $E$. coli from fecal specimens of poultry and from clinical specimens of human to provide some baseline data in this perspective.

\section{Materials \& Methods}

\section{Sample collection}

Clinical specimens were collected from a local clinic at Savar, Dhaka. Poultry fecal samples were collected from four poultry farms of Savar, Dhaka. Microbiological work was carried out at Department of Microbiology, Jahangirnagar University, Dhaka. Molecular work was carried out at Environmental laboratory, icddr, b, Dhaka, Bangladesh.

We have collected 48 human clinical specimens (urine) from a local clinic and 40 fresh chicken droppings from four poultry farms (ten samples from each). The timeline for specimen collection was from April-2012 to September-2012. Organisms were isolated and identified through a series of biochemical tests according to standard procedures [11].

\section{Antibiotic sensitivity test}

Antibiotic susceptibility test was done with amoxicillin $(10 \mu \mathrm{g})$, tetracycline $(30 \mu \mathrm{g})$, sulfamethoxazole-trimethoprim $(23.75+1.25 \mu \mathrm{g})$, ciprofloxacin $(5 \mu \mathrm{g})$, levofloxacin $(5 \mu \mathrm{g})$ and nitrofurantoin $(300 \mu \mathrm{g})$ disks (Oxoid) by disk diffusion method. ESBL screening was done by double disc synergy (DDS) method [12].

\section{Molecular analysis}

Molecular characterization of ESBL genes (bla ${ }_{\mathrm{CTX}-\mathrm{M}}$, bla $\mathrm{SHV}_{\mathrm{H}}$, $b l a_{\text {TEM }}$, and $b l a_{\text {OXA }}$ ) of 25 isolates were done through PCR. The PCR primers, annealing temperature and PCR condition used in this study were maintained according to references [13-16]. 


\section{Results}

14 E. coli and 11 E. coli were identified respectively from clinical and poultry specimens. Out of 25 isolates, $23 \mathrm{E}$. coli were multidrug resistant, i.e. resistant against at least three different groups of antibiotics. Highest level of resistance was against amoxicillin (Table $1)$.

DDS method showed that all E. coli from poultry origin and $78 \% E$. coli from clinical specimens were resistant to amoxicillin clavulanic acid, therefore, inhibited the synergistic effect of clavulanate and cephalosporin against the ESBL and gave negative DDS results. No $E$. coli were true ESBL producers, but they showed the inhibitor resistant $\beta$-lactamase phenotype.

In the PCR, E. coli of poultry origin were found to carry only bla $_{\text {TEM }}$ gene. E. coli from human origin carried three types of $\beta$ lactamase genes (bla ${ }_{\text {TEM }}, \mathrm{n}=7$; bla $_{\text {CTX-M }}, \mathrm{n}=2$; and bla OXA $_{\mathrm{O}}, \mathrm{n}=1$ ) except bla $_{\mathrm{SHV}}$.

\begin{tabular}{|l|l|l|}
\hline Antibiotic tested & $\begin{array}{l}\text { \% of resistance } \\
\text { (Human origin) }\end{array}$ & $\begin{array}{l}\text { \% of resistance } \\
\text { (Poultry origin) }\end{array}$ \\
\hline Amoxicillin & $100 \%$ & $100 \%$ \\
\hline Tetracycline & $73.3 \%$ & $100 \%$ \\
\hline $\begin{array}{l}\text { Sulfamethoxazole- } \\
\text { trimethoprim }\end{array}$ & $90 \%$ & $92.3 \%$ \\
\hline Nitrofurantoin & $40 \%$ & $30.8 \%$ \\
\hline Ciprofloxacin & $80 \%$ & $84.6 \%$ \\
\hline Levofloxacin & $66.7 \%$ & $77 \%$ \\
\hline
\end{tabular}

Table 1: E. coli from both human and poultry origin showed high level of resistance against commonly used antibiotics.

\section{Discussion}

In our study more than $80 \%$ of $E$. coli from chicken and human specimens were multidrug resistant. The antibiogram result showed complete resistance of all $E$. coli to amoxicillin and E. coli from chicken were also completely resistant to tetracycline. In previous studies carried out on $E$. coli from poultry environment in Bangladesh showed resistance to penicillin (i.e. amoxicillin and ampicillin) in a range of $28 \%-88 \%$ and to tetracycline $45.5 \%$ to $58 \%[7,8]$. Though lowest level of resistance $(30.8 \%)$ was found against nitrofurantoin for $E$. coli of chicken origin, but it is still a matter of concern that how these isolates become resistant to this broad spectrum of antibiotic which is mostly used for human treatment purpose. All of the chicken E. coli and 78\% of clinical $E$. coli were resistant to amoxicillin/clavulanic acid, thus DDS result was negative for ESBL phenotype and positive for inhibitor resistance phenotype. The genotype bla $a_{\mathrm{TEM}}$ was the most prevalent (78\%) genotype in all types of $E$. coli. Both phenotype and genotype is indicative of the presence of inhibitor resistance TEM type $\beta$-lactamase enzyme, however, sequencing of these genes might be more conclusive. In our study, chicken droppings were collected from healthy chicken and thus E. coli from these specimens can be described as nonpathogenic. Still high level of antibiotic resistance was found among these isolates. Moreover, all the E. coli from chicken showed similar phenotype (inhibitor resistance) and genotype $\left(b / a_{\mathrm{TEM}}\right)$. These non pathogenic but resistance gene containing $E$. coli can easily enter the environment and as many antibiotic resistance genes including bla TEM $_{\mathrm{T}}$ are plasmid mediated, they can be easily transferred between and within bacterial species [6]. Thus nonpathogenic fecal origin $E$. coli have potential to transfer the resistant genes to pathogenic strains of $E$. coli and other compatible bacteria within the environment. The chicken $E$. coli can also cross-contaminate the meat and can directly enter the human body through food chain as previously reported [6,7]. The E. coli from clinical specimens were pathogenic as they were collected from infected patients' urine. The prevalence of inhibitor type beta lactamase phenotype (78\%) in E. coli from clinical specimens was detected like the chicken derived E. coli. Presence of bla $a_{\text {TEM }}$ was also highest $(50 \%, \mathrm{n}=7)$ among $E$. coli from human origin. Though the genetic similarity between the resistant genes of chicken origin and human origin were not explored, still detection of same phenotype and $\beta$-lactamases genotype among the $E$. coli from both sources strongly suggest epidemiological linkage which is highly significant. Also SHV is a $\beta$-lactamase known to be frequent in clinical isolates [17], however, none of our clinical isolates harboured blkasHV. The reason behind high prevalence of inhibitor resistance $\beta$-lactamase enzyme is unclear. If not controlled, transmission of multidrug resistance and beta lactamase genes from poultry environment to the human community can be a major public health challenge for Bangladesh as found in other countries [6,7]. Infection with drug resistant bacteria leads to higher mortality and treatment cost and has serious public health implications [18]. Such prevalence of antibiotic resistance demands continuous surveillance to determine the causes, sources and transmission of resistance.

\section{Impacts}

- High prevalence of inhibitor resistant $\beta$-lactamase phenotype and genotype has been found in E. coli isolated from poultry fecal specimens and human clinical specimens.

- Isolated E. coli from both sources also showed multi drug resistance against commonly used antibiotics.

- Transfer of resistance genes from poultry environment to human community and vice versa can happen and demands surveillance.

\section{Acknowledgement}

Authors acknowledge the support of environmental laboratory, icddr, $b$ for genotyping analysis.

\section{References}

1. Rahman M, Shoma S, Rashid H, Siddique AK, Nair GB, et al. (2004) Extended-spectrum beta-lactamase-mediated third-generation cephalosporin resistance in Shigella isolates in Bangladesh. J Antimicrob Chemother 54: 846-847.

2. Adnan N, Sultana M, Islam OK, Nandi SP, Hossain MA (2013) Characterization of Ciprofloxacin resistant Extended Spectrum [Beta]Lactamase (ESBL) producing Escherichia spp. from clinical waste water in Bangladesh. Advances in Bioscience and Biotechnology 4: 15.

3. Talukdar PK, Rahman M, Rahman M, Nabi A, Islam Z, et al. (2013) Antimicrobial resistance, virulence factors and genetic diversity of Escherichia coli isolates from household water supply in Dhaka, Bangladesh. PLoS One 8: e61090.

4. Saber MH, Barai L, Haq JA, Jilani MSA, Begum J (2010) The pattern of organism causing urinary tract infection in diabetic and non-diabetic patients in Bangladesh. Bangladesh Journal of Medical Microbiology 4: 6-8.

5. Okeke IN, Lamikanra A, Edelman R (1999) Socioeconomic and behavioral factors leading to acquired bacterial resistance to antibiotics in developing countries. Emerg Infect Dis 5: 18-27. 
Citation: Parvez Md. AK, Marzan M, Liza SM, Mou TJ, Azmi IJ, et al. (2016) Prevalence of Inhibitor Resistant Beta Lactamase Producing E. coli in Human and Poultry Origin of Bangladesh. J Bacteriol Parasitol 7: 271. doi:10.4172/2155-9597.1000271

Page 3 of 3

6. Harada K, Asai T (2010) Role of antimicrobial selective pressure and secondary factors on antimicrobial resistance prevalence in Escherichia coli from food-producing animals in Japan. J Biomed Biotechnol 2010: 180682.

7. Hasan B, Sandegren L, Melhus A, Drobni M, Hernandez J, et al. (2012) Antimicrobial drug-resistant Escherichia coli in wild birds and free-range poultry, Bangladesh. Emerg Infect Dis 18: 2055-2058.

8. Hasan B, Faruque R, Drobni M, Waldenström J, Sadique A (2011) High prevalence of antibiotic resistance in pathogenic Escherichia coli from large-and small-scale poultry farms in Bangladesh. Avian Dis 55: 689-692.

9. Overdevest I1, Willemsen I, Rijnsburger M, Eustace A, Xu L, et al. (2011) Extended-spectrum $\beta$-lactamase genes of Escherichia coli in chicken meat and humans, The Netherlands. Emerg Infect Dis 17: 1216-1222.

10. Leverstein-van Hall MA, Dierikx CM, Cohen SJ, Voets GM, van den Munckhof MP, et al. (2011) Dutch patients, retail chicken meat and poultry share the same ESBL genes, plasmids and strains. Clin Microbiol Infect 17: 873-880.

11. Cheesbrough M (2006) District laboratory practice in tropical countries Cambridge University Press.

12. Jarlier V, Nicolas MH, Fournier G, Philippon A (1988) Extended broadspectrum beta-lactamases conferring transferable resistance to newer beta-lactam agents in Enterobacteriaceae: hospital prevalence and susceptibility patterns. Rev Infect Dis 10: 867-878.

13. Rotimi VO, Jamal W, Pal T, Sovenned A, Albert MJ (2008) Emergence of CTX-M-15 type extended-spectrum beta-lactamase-producing Salmonella spp. in Kuwait and the United Arab Emirates. J Med Microbiol 57: 881-886.

14. Brinas L, Zarazaga M, Sáenz Y, Ruiz-Larrea F, Torres C (2002) Betalactamases in ampicillin-resistant Escherichia coli isolates from foods, humans, and healthy animals. Antimicrob Agents Chemother 46: 3156-3163.

15. Li R, Lai J, Wang Y, Liu S, Li Y, et al. (2013) Prevalence and characterization of Salmonella species isolated from pigs, ducks and chickens in Sichuan Province, China. Int J Food Microbiol 163: 14-18.

16. Pagani L, Dell'Amico E, Migliavacca R, D'Andrea MM, Giacobone E, et al. (2003) Multiple CTX-M-Type Extended-Spectrum $\beta$-Lactamases in Nosocomial Isolates of Enterobacteriaceae from a Hospital in Northern Italy. J Clin Microbiol 41: 4264-4269.

17. Paterson DL, Bonomo RA (2005) Extended-spectrum beta-lactamases: a clinical update. Clin Microbiol Rev 18: 657-686.

18. Cosgrove SE (2006) The relationship between antimicrobial resistance and patient outcomes: mortality, length of hospital stay, and health care costs. Clin Infect Dis 42: S82-S89. 